\title{
Response to Therapy in Breast Cancer
}

\author{
Norbert Avril ${ }^{1}$, Stefanie Sassen ${ }^{2}$, and Rebecca Roylance ${ }^{3}$ \\ ${ }^{1}$ Department of Nuclear Medicine, Barts and The London School of Medicine, Queen Mary, University of London, London, \\ United Kingdom; ${ }^{2}$ Department of Pathology, Technische Universität München, Munich, Germany; and ${ }^{3}$ Centre for \\ Molecular Oncology and Imaging, Institute of Cancer, Barts and the London School of Medicine and Dentistry, London, \\ United Kingdom
}

Increasing numbers of patients with newly diagnosed breast cancer receive primary systemic therapy followed by surgery. Histopathology provides an accurate assessment of treatment efficacy on the basis of the extent of residual tumor and regressive changes within tumor tissue. However, only approximately $20 \%$ of breast cancer patients achieve a pathologic complete response, a fact that necessitates methods for monitoring therapeutic effectiveness early during therapy. ${ }^{18} \mathrm{~F}$-FDG PET and ${ }^{18} \mathrm{~F}-\mathrm{FDG} \mathrm{PET} / \mathrm{CT}$ provide essential information regarding a response to primary chemotherapy. Patients with low tumor metabolic activity on pretreatment ${ }^{18} \mathrm{~F}-\mathrm{FDG}$ PET are not likely to achieve a histopathologic response. The degree of changes in ${ }^{18} \mathrm{~F}-\mathrm{FDG}$ uptake after the initiation of therapy is correlated with the histopathologic response after the completion of therapy. Thus, tumor metabolic changes assessed early during therapy predict therapeutic effectiveness in individual patients. Early identification of ineffective therapy also might be helpful in patients with metastatic breast cancer because many palliative treatment options are available. Changes in metabolic activity generally occur earlier than changes in tumor size, which is the current standard for the assessment of a response. Although treatment stratification based on a metabolic response is an exciting potential application of PET, specific PET response assessment criteria still need to be developed and validated on the basis of patient outcomes before changes in treatment regimens can be implemented. There is increasing clinical evidence for metastatic breast cancer and other tumors that ${ }^{18} \mathrm{~F}-\mathrm{FDG}$ PET/ $\mathrm{CT}$ is the most accurate imaging procedure for assessment of the response at the end of treatment when both CT information and tumor metabolic activity are considered. Importantly, in the setting of primary chemotherapy, neither PET/CT nor conventional imaging procedures can assess the extent of residual breast cancer as accurately as histopathology. Observation of changes in tumor blood flow or tumor cell proliferation is an additional encouraging approach for predicting a response. Ultimately, the prediction of therapeutic effectiveness by PET and PET/CT could help to individualize treatment and to avoid ineffective chemotherapies, with their associated toxicities.

Key Words: breast cancer; treatment monitoring; histopathology; ${ }^{18} \mathrm{~F}-\mathrm{FDG} ;{ }^{15} \mathrm{O}$-water; PET/CT

J Nucl Med 2009; 50:55S-63S

DOI: 10.2967/jnumed.108.057240

Received Jan. 13, 2009; revision accepted Feb. 25, 2009.

For correspondence or reprints contact: Norbert Avril, Department of Nuclear Medicine, Barts and The London School of Medicine, Queen Mary, University of London, West Smithfield (QE II), London EC1A 7BE, United Kingdom.

E-mail: n.e.avril@qmul.ac.uk

COPYRIGHT $\odot 2009$ by the Society of Nuclear Medicine, Inc. he treatment of newly diagnosed breast cancer is primarily determined by the extent of disease and generally includes surgery - either breast-conserving surgery, usually combined with postoperative radiation therapy, or total mastectomy. Axillary lymph node dissection has now been replaced by sentinel lymph node biopsy in many patients presenting without clinically apparent axillary tumor involvement. Adjuvant systemic therapy after surgery is frequently recommended to reduce the risk of tumor recurrence, especially in patients with lymph nodes showing positive findings, tumors larger than $1 \mathrm{~cm}$, or other unfavorable prognostic features.

Primary systemic chemotherapy was first introduced for managing inoperable and large or locally advanced breast tumors (1). It is also now increasingly being used for tumors that, although operable, would require mastectomy; therefore, it is used to try to reduce tumor size and therefore permit breast-conserving surgery. In this situation, the term "neoadjuvant chemotherapy" is often used. The primary aim of treatment is a reduction in tumor volume (2), but disease-free survival, overall survival, and locoregional control are similar to those achieved with initial surgery followed by conventional adjuvant chemotherapy (3).

Primary systemic chemotherapy followed by surgery allows for assessment of the histopathologic response. Although approximately $70 \%$ of patients demonstrate a clinical response either on physical examination or on anatomic imaging, only $3 \%-27 \%$ achieve a complete histopathologic response $(2,4-6)$. The degree of the response provides important prognostic information, and patients achieving a complete pathologic response show significantly longer disease-free overall and overall survival than nonresponders $(7,8)$.

A recent review of data presented at the National Cancer Institute State of the Science Conference on preoperative therapy in invasive breast cancer indicated that preoperative systemic therapy in operable breast cancer is effective and can improve breast conservation rates (9). A variety of clinical, imaging, and pathologic measurements can be used to assess the response of a tumor to treatment; in particular, a pathologic complete response may be useful as a surrogate endpoint in the evaluation of new therapies. However, at 
present, there are no data to suggest that systemic treatment should be tailored on the basis of the initial tumor response or the extent of residual disease.

For patients with metastatic breast cancer, several therapeutic options are available $(10,11)$. The choice of treatment depends on histopathologic tumor features - that is, whether tumors are estrogen receptor positive or human epidermal growth factor receptor 2 (HER2) positive-and the extent of disease. Three groups of tumors are generally treated with different regimens: triple-negative breast cancer, which is defined as estrogen receptor-negative, progesterone receptornegative, and HER2-negative tumors; HER2-positive tumors; and estrogen receptor-positive tumors. The only current treatment option for patients with triple-negative tumors is chemotherapy (12), patients with HER2-positive tumors can be treated with a combination of trastuzumab and chemotherapy (13), and patients with estrogen receptorpositive tumors and a small volume of metastatic disease are considered for treatment with endocrine agents (11).

\section{ASSESSMENT OF RESPONSE TO TREATMENT}

Histopathology is often used as the reference standard for assessing the response to primary chemotherapy in breast cancer. However, there is no single definition of a histopathologic response, and response criteria vary among studies. Most commonly, a pathologic complete response is defined by the absence of residual invasive tumor $(2,5,6)$. A modified classification was suggested by Honkoop et al., who found no difference in survival between patients with scattered microscopic foci of residual tumor cells and patients who achieved a pathologic complete response (14). These 2 groups of responses were combined into a response category referred to as "minimal residual disease," and all other responses were classified as "gross residual disease."

Other response classifications include changes in tumor cellularity (15-17) and the presence of regressive changes in residual tumor tissue $(18,19)$. However, regressive morphologic features, such as hyaline fibrosis, inflammatory cell infiltrates, iron-storing macrophages, or calcifications, are observed in approximately $50 \%$ of cases after chemotherapy $(6,20)$ and have limited sensitivity $(7 \%-67 \%)$ and specificity $(48 \%-99 \%)$ compared with nontreated tumor specimens $(6,21)$. Although the extent of residual viable tumor is the most important predictor of long-term outcome $(2,8,15,22-25)$, histopathologic response criteria have distinct limitations. The rate of complete pathologic response is relatively low, ranging from $3 \%$ to $27 \%$ (2,4-6). Between $13 \%$ and $25 \%$ of patients will experience a systemic recurrence during 5 y of follow-up $(8,23,26,27)$. Furthermore, a subgroup of patients classified as not showing a histopathologic response will remain disease free but have not been recognized by current histopathologic criteria.

In the absence of tissue specimens, generally the case in the setting of metastatic disease, the most frequently used surrogate endpoint for a therapeutic effect is a change in tumor size. The Response Evaluation Criteria in Solid Tumors (RECIST) define a response as a decrease in the maximum tumor diameter of at least $30 \%$ (28). Anatomic imaging, predominantly CT, MRI, and ultrasound, is used to obtain measurements of reference tumor lesions before and after treatment for response assessment and follow-up.

Variable results have been found for the agreement between anatomic imaging and pathologic tumor size (29). A large retrospective review found no evidence that mammography or ultrasound performed better than physical examination in measuring residual disease after chemotherapy (29). Breast MRI has been found to be more accurate for estimating the extent of residual disease (30). However, MRI cannot rule out residual tumor tissue with sufficient accuracy (30-34). Another approach currently under investigation is dynamic contrast-enhanced MRI. More than a $65 \%$ reduction in tumor volume and a reduction in the early enhancement ratio after 2 cycles of chemotherapy were associated with a histopathologic response (35). Combining both criteria yielded a diagnostic accuracy of $93 \%$ for identifying tumors showing a pathologic complete response (35).

The use of RECIST is established for response assessment in the setting of metastatic disease. However, several cycles of treatment are needed before a change in tumor size can be assessed by anatomic imaging. Moreover, changes in the sizes of metastases in bone and liver, which are the most common sites of breast cancer metastases, are difficult to evaluate.

\section{MONITORING RESPONSE TO TREATMENT WITH ${ }^{18} \mathrm{~F}-\mathrm{FDG}$ PET AND PET/CT}

\section{Metabolic Response to Primary Systemic Therapy of Breast Cancer}

The prediction of a response to treatment refers to the early identification of treatment effectiveness through a comparison of the levels of radiotracer uptake before and after 1 or 2 cycles of systemic therapy. The concept of using ${ }^{18} \mathrm{~F}$-FDG PET for predicting a therapeutic response is based on early changes in tumor glucose use and the close correlation of changes in ${ }^{18} \mathrm{~F}-\mathrm{FDG}$ uptake with the effectiveness of treatment $(36,37)$. At least 2 sequential ${ }^{18} \mathrm{~F}-\mathrm{FDG}$ PET scans are currently necessary for the prediction of a treatment response; one is obtained before treatment to serve as a baseline, and one is obtained after the initiation of chemotherapy, for example, after the first or second cycle.

Fifteen years ago, Wahl et al. (36) reported on changes in tumor metabolic activity in a series of 11 women who had locally advanced primary breast cancers and who had received a combination of primary chemotherapy and hormone therapy. Tumor ${ }^{18} \mathrm{~F}-\mathrm{FDG}$ uptake promptly decreased in 8 patients, with subsequent partial or complete pathologic responses, whereas tumors in 3 nonresponding patients did not show a significant decrease in ${ }^{18} \mathrm{~F}-\mathrm{FDG}$ uptake. Later studies confirmed a more pronounced decrease in ${ }^{18} \mathrm{~F}$-FDG uptake (standardized uptake value 
[SUV]) after the first and second cycles of primary chemotherapy in patients showing a histopathologic response than in nonresponders (38-40). Among a series of 22 patients, all responders were correctly identified after the first cycle of primary chemotherapy by a decrease in the SUV of greater than 55\% compared with the baseline (38). The accuracies for the prediction of a histopathologic response were $88 \%$ after the first cycle of chemotherapy and $91 \%$ after the second cycle. In another study, 30 breast cancer patients received 8 cycles of primary chemotherapy, and the mean reduction in ${ }^{18} \mathrm{~F}-\mathrm{FDG}$ uptake after the first cycle was significantly higher in lesions with a partial, complete macroscopic or complete microscopic response than in nonresponding lesions (39). In a recent report, 64 breast cancer patients underwent ${ }^{18} \mathrm{~F}-\mathrm{FDG}$ PET after the first, second, and third cycles of chemotherapy (40). Relative changes in tumor ${ }^{18} \mathrm{~F}$-FDG uptake were superior to alterations in tumor size for monitoring a treatment response. A decrease in ${ }^{18} \mathrm{~F}$-FDG uptake (SUV) of $40 \%$ predicted a histopathologic response with accuracies of $77 \%$ after the first cycle of chemotherapy and $87 \%$ after the second cycle. Table 1 summarizes trials reporting on the prediction of a histopathologic response by ${ }^{18} \mathrm{~F}-\mathrm{FDG}$ PET.

In comparisons of those studies, the definition of a treatment response as a reference for a metabolic response is critical. Importantly, the histopathologic response criteria used in those PET studies varied widely, with response rates ranging from $16.3 \%$ to $55.6 \%$ (38-41). Translation of the observations described earlier into clinical practice is currently difficult because there is no agreement about the optimal timing of PET, that is, whether it should be performed after the first, second, or third cycle of chemotherapy. In addition, different thresholds for the relative changes in tumor metabolic activity (SUV) used to predict a response were used in those PET studies. Although it is essential to investigate the ability of ${ }^{18} \mathrm{~F}-\mathrm{FDG}$ PET to identify patients responding to systemic therapy, the detection of a treatment failure might be clinically more important.

A recent prospective multicenter trial in which $272{ }^{18} \mathrm{~F}-$ FDG PET scans were performed for 104 patients confirmed that the greater the reduction in tumor metabolic activity early in the course of therapy, the more likely that patients would achieve a histopathologic response (42). In patients who showed a histopathologic response, the SUV decreased by $50.5 \% \pm 18.4 \%$ (mean $\pm \mathrm{SD}$ ) after the first cycle of primary chemotherapy; in comparison, the SUV decreased by $36.5 \% \pm 20.9 \%$ in nonresponders. Patients who did not show a histopathologic response were identified with a negative predictive value of $89.5 \%$ after the first cycle of therapy when a relative decrease in the SUV of less than $45 \%$ was used as a cutoff. Correspondingly, the negative predictive value after the second cycle of therapy was $88.9 \%$ when the cutoff was a 55\% decrease in the SUV. Interestingly, a metabolic response after one cycle of therapy predicted outcomes in patients regardless of whether they continued to receive a combination of epirubicin and paclitaxel or received a planned switch to epirubicin followed by paclitaxel. A high negative predictive value is essential for clinical decision making to ensure the continuation of treatment in all patients potentially responding to therapy.

An important observation of this multicenter trial (42) is that ${ }^{18}$ F-FDG PET identified patients with low tumor metabolic activity before treatment as not achieving histopathologic response. Twenty-four of 104 breast carcinomas (23\%) had a baseline SUV of less than 3.0, and none responded to chemotherapy. These tumors were more likely to be well differentiated and estrogen receptor positive. These findings mean that breast cancers with low metabolic activity identified by ${ }^{18} \mathrm{~F}$-FDG PET before treatment are not likely to respond to primary chemotherapy. Therefore, for patients with such cancers, it is possible that initial management should be different; for example, if the cancers are operable, patients should undergo surgery immediately or perhaps should have primary hormone therapy. These findings are supported by the results of smaller series additionally reporting that it is difficult to measure changes in ${ }^{18} \mathrm{~F}$-FDG uptake in tumors with low pretherapy ${ }^{18} \mathrm{~F}-\mathrm{FDG}$ uptake $(40,41,43)$. In the multicenter trial $(43)$, a positive correlation was also found between the histopathologic response and the level of ${ }^{18} \mathrm{~F}-\mathrm{FDG}$ uptake after the first and second cycles of chemotherapy, but no defined SUV threshold was clearly superior for the optimal separation of responders and nonresponders during chemotherapy.

The main rationale for primary chemotherapy is to test for chemosensitivity, allowing for subsequent changes in the chemotherapy regimen, with the aim of designing a more individualized treatment plan. In the only trials in which early changes in primary chemotherapy were implemented, a clinical response was used to guide treatment decisions $(16,44,45)$. It is still unclear which patients would benefit most from an early change in treatment, such as a switch to a non-cross-resistant or second-line chemotherapy regimen, because there was no advantage of a switch for most nonresponders (45). Nevertheless, patients showing a clinical response to primary chemotherapy benefited from either the addition of a non-cross-resistant chemotherapeutic agent (such as a taxane) or prolonged treatment $(4,46)$. For the establishment of therapy modifications based on response assessments during chemotherapy, a tool more suitable than the clinical response is desirable. Metabolic PET could serve as such a method and could provide a clinically useful surrogate endpoint. There is clearly a need for prospective randomized trials to evaluate and validate PET-guided treatment stratification for identifying subsets of patients who would benefit most from early treatment modifications.

\section{Metabolic Response to Therapy of Metastatic Breast Cancer}

There are significant differences between the goals of primary systemic therapy of newly diagnosed breast cancer and the goals of treatment of metastatic disease. Generally, 
TABLE 1. Prediction of Histopathologic Response of Primary Breast Cancer by Relative Changes in ${ }^{18}$ F-FDG Uptake on ${ }^{18}$ F-FDG PET

\begin{tabular}{|c|c|c|c|c|c|c|c|}
\hline $\begin{array}{l}\text { Tumor type } \\
\text { or stage }\end{array}$ & Study & Year & $\begin{array}{l}\text { No. of } \\
\text { patients }\end{array}$ & PET timing & PET criterion* & Accuracy $^{\dagger}$ & Response rate \\
\hline \multirow[t]{2}{*}{ LABC } & \multirow[t]{2}{*}{$\begin{array}{l}\text { Schelling } \\
\text { et al. (38) }\end{array}$} & \multirow[t]{2}{*}{2000} & \multirow[t]{2}{*}{22} & $\begin{array}{l}\text { After first } \\
\text { cycle }\end{array}$ & $55 \%$ & $88 \%$ & \multirow[t]{2}{*}{ 7/22 (29\%) } \\
\hline & & & & $\begin{array}{l}\text { After second } \\
\text { cycle }\end{array}$ & $55 \%$ & $91 \%$ & \\
\hline $\begin{array}{l}\text { Large } \\
\qquad(>3 \mathrm{~cm}) \\
\text { and LABC }\end{array}$ & $\begin{array}{l}\text { Smith } \\
\text { et al. (39) }\end{array}$ & 2000 & 30 & $\begin{array}{l}\text { After first } \\
\text { cycle }\end{array}$ & $20 \% \S$ & $\begin{array}{l}80 \%{ }^{\text {Il }} \text { (sens, } 90 \% ; \\
\text { spec, } 74 \% \text { ) }\end{array}$ & $11 / 30$ (38\%) \\
\hline \multirow[t]{2}{*}{$\begin{array}{l}\text { Stages II } \\
\text { and III }\end{array}$} & \multirow[t]{2}{*}{$\begin{array}{l}\text { Rousseau } \\
\text { et al. (40) }\end{array}$} & \multirow[t]{2}{*}{2006} & \multirow[t]{2}{*}{64} & $\begin{array}{l}\text { After first } \\
\text { cycle }\end{array}$ & $40 \%$ & $77 \%$ & \multirow[t]{2}{*}{$36 / 64$ (56\%) } \\
\hline & & & & $\begin{array}{l}\text { After second } \\
\text { cycle }\end{array}$ & $40 \%$ & $87 \%$ & \\
\hline \multirow{2}{*}{$\begin{array}{l}\text { Large } \\
\qquad>3 \mathrm{~cm}) \\
\text { and LABC }\end{array}$} & \multirow[t]{2}{*}{$\begin{array}{r}\text { McDermott } \\
\text { et al. (41) }\end{array}$} & \multirow[t]{2}{*}{2007} & \multirow[t]{2}{*}{96} & $\begin{array}{l}\text { After first } \\
\text { cycle }\end{array}$ & $24 \%$ & $\begin{array}{l}65 \% \text { ฯ (sens, } 100 \% \\
\text { spec, } 53 \% \text { ) }\end{array}$ & $13 / 51(25 \%)^{\|}$ \\
\hline & & & & Midtherapy & $58 \%$ & $\begin{array}{l}78 \% \text { ๆl (sens, } 100 \% ; \\
\text { spec, } 68 \% \text { ) }\end{array}$ & $14 / 45(31 \%)^{\|}$ \\
\hline \multirow{2}{*}{$\begin{array}{l}\text { Large } \\
\qquad(>3 \mathrm{~cm}) \\
\quad \text { and LABC }\end{array}$} & \multirow[t]{2}{*}{$\begin{array}{l}\text { Schwarz-Dose } \\
\text { et al. (42) }\end{array}$} & \multirow[t]{2}{*}{2008} & \multirow[t]{2}{*}{104} & $\begin{array}{l}\text { After first } \\
\text { cycle }\end{array}$ & $45 \%$ & $65 \%$ & \multirow[t]{2}{*}{ 17/104 (16\%) } \\
\hline & & & & $\begin{array}{l}\text { After second } \\
\text { cycle }\end{array}$ & $55 \%$ & $64 \%$ & \\
\hline LABC & $\begin{array}{l}\text { Dunnwald } \\
\text { et al. (59) }\end{array}$ & 2008 & 53 & $\begin{array}{l}\text { Midtherapy } \\
\text { (9 wk after } \\
\text { initiation) }\end{array}$ & $\begin{array}{c}5 \% \text { increase } \\
\text { in tumor } \\
\text { blood flow } \\
\text { (vs. } 5 \% \text { decrease) }\end{array}$ & $\begin{array}{l}\text { Hazard ratio, } \\
1.7(P<0.001)\end{array}$ & Overall survival \\
\hline
\end{tabular}

${ }^{*}$ Reported as cutoff for relative decrease in SUV, unless otherwise indicated.

${ }^{\dagger}$ Accuracy of ${ }^{18} \mathrm{~F}$-FDG PET for prediction of histopathologic response. sens = sensitivity; spec = specificity.

${ }^{\ddagger}$ Outcome measure was histopathologic response.

$\$ 18$ F-FDG uptake was measured as dosage uptake rate instead of SUV.

IValue was not given in publication; accuracy was calculated on basis of sensitivity, specificity, and response rate.

"Pathologic response rate among patients who underwent PET at indicated point in therapy; overall response rate was not given.

$\mathrm{LABC}=$ locally advanced breast cancer.

All studies summarized in this table were prospectively designed.

a few chemotherapeutic regimens are used for primary systemic therapy, but many palliative treatment options are available for metastatic disease. Histopathology is used as a surrogate endpoint for the validation of primary chemotherapy, whereas almost always no tissue specimens are available from metastatic disease for the evaluation of a response.

Only a few studies have reported on the clinical utility of sequential ${ }^{18} \mathrm{~F}$-FDG PET in patients with metastatic disease. A decrease in tumor ${ }^{18} \mathrm{~F}-\mathrm{FDG}$ uptake was observed in 8 of 12 patients who had metastatic disease and who responded after the first cycle of chemotherapy (47). In another study, a rapid decrease in tumor glucose metabolism was observed after the first cycle of therapy in 6 of 9 responding patients, but there was no substantial decrease in nonresponding patients (48). Specht et al. (49) retrospectively reviewed 28 patients who underwent serial ${ }^{18} \mathrm{~F}-$ FDG PET during systemic therapy for bone-dominant metastatic breast cancer. The treatments were heterogeneous, including endocrine therapy, chemotherapy, biologic therapy, and bisphosphonates. Smaller relative decreases in the SUV (or increases in the SUV) were associated with a shorter time to progression. A patient with no change in the SUV was twice as likely to progress as a patient with a $42 \%$ median decrease in the SUV (49). Table 2 summarizes trials reporting on the prediction of a response in metastatic breast cancer by ${ }^{18} \mathrm{~F}$-FDG PET.

The results of a recent study confirmed previous observations on the predictive value of information about early changes in glucose metabolism for metastatic breast cancer (50). Compared with the baseline PET data, the ${ }^{18} \mathrm{~F}-\mathrm{FDG}$ uptake in responding metastatic lesions decreased to $72 \% \pm$ $21 \%$ after the first cycle of chemotherapy and to $54 \% \pm$ $16 \%$ after the second cycle. In contrast, the ${ }^{18} \mathrm{~F}-\mathrm{FDG}$ uptake in metastases not responding to chemotherapy declined only to $94 \% \pm 19 \%$ after the first cycle of chemotherapy and to $79 \% \pm 9 \%$ after the second cycle. ${ }^{18} \mathrm{~F}-\mathrm{FDG}$ PET correctly predicted the responses in all patients after the first cycle of chemotherapy and was more accurate than conventional imaging procedures after the third cycle of chemotherapy. As discussed earlier, patients would poten- 


\begin{tabular}{|c|c|c|c|c|c|c|c|c|c|}
\hline $\begin{array}{l}\text { Tumor type } \\
\text { or stage }\end{array}$ & Authors & Year & $\begin{array}{c}\text { No. of } \\
\text { patients }\end{array}$ & $\begin{array}{l}\text { PET } \\
\text { timing }\end{array}$ & $\begin{array}{c}\text { PET } \\
\text { criterion }\end{array}$ & $\begin{array}{l}\text { Outcome } \\
\text { measure }\end{array}$ & Design & $\begin{array}{c}\text { PET } \\
\text { performance }\end{array}$ & $\begin{array}{l}\text { Response } \\
\text { rate }\end{array}$ \\
\hline $\begin{array}{l}\text { Bone- } \\
\text { dominant } \\
\text { metastatic } \\
\text { breast } \\
\text { cancer }\end{array}$ & $\begin{array}{l}\text { Specht } \\
\text { et al. (49) }\end{array}$ & 2007 & 28 & $\begin{array}{l}\text { During } \\
\text { treatment }\end{array}$ & $\begin{array}{l}\text { No change } \\
\text { in SUV } \\
\text { (vs. } 42 \% \\
\text { decrease) }\end{array}$ & $\begin{array}{l}\text { Disease } \\
\text { progression }\end{array}$ & $\begin{array}{l}\text { Retro- } \\
\text { spective }\end{array}$ & $\begin{array}{c}\text { Hazard } \\
\text { ratio, } 2.2 \\
(P=0.006)\end{array}$ & $13 / 28(46 \%)^{\star}$ \\
\hline \multirow{3}{*}{$\begin{array}{l}\text { Metastatic } \\
\text { breast } \\
\text { cancer }\end{array}$} & $\begin{array}{l}\text { Dose Schwarz } \\
\text { et al. (50) }\end{array}$ & 2005 & 11 & $\begin{array}{l}\text { After first } \\
\text { cycle }\end{array}$ & $\begin{array}{l}\text { Visual } \\
\text { analysis }\end{array}$ & $\begin{array}{l}\text { Clinical } \\
\text { response }^{\dagger}\end{array}$ & Prospective & $\begin{array}{c}\text { Accuracy, } \\
100 \%\end{array}$ & $6 / 11(55 \%)^{\ddagger}$ \\
\hline & & & & $\begin{array}{l}\text { After first } \\
\text { cycle }\end{array}$ & $\begin{array}{l}\text { Relative } \\
\text { decrease } \\
\text { in SUV }\end{array}$ & $\begin{array}{l}\text { Clinical } \\
\quad \text { response }^{\dagger}\end{array}$ & & $\begin{array}{c}28 \% \text { vs. } 6 \% \\
(P=0.02)^{\S}\end{array}$ & \\
\hline & & & & $\begin{array}{l}\text { After } \\
\text { second } \\
\text { cycle }\end{array}$ & $\begin{array}{l}\text { Relative } \\
\text { decrease } \\
\text { in SUV }\end{array}$ & $\begin{array}{l}\text { Clinical } \\
\text { response }^{\dagger}\end{array}$ & & $\begin{array}{c}46 \% \text { vs. } 21 \% \\
(P=0.003)^{\S}\end{array}$ & \\
\hline $\begin{array}{l}\text { Metastatic } \\
\text { breast } \\
\text { cancer }\end{array}$ & $\begin{array}{l}\text { Gennari } \\
\text { et al. (48) }\end{array}$ & 2000 & 9 & $\begin{array}{l}\text { After first } \\
\text { cycle }\end{array}$ & $\begin{array}{l}\text { Absolute } \\
\text { decrease } \\
\text { in SUV }\end{array}$ & $\begin{array}{l}\text { Clinical or } \\
\quad \text { radiographic } \\
\text { response }\end{array}$ & Prospective & $\begin{array}{c}\text { SUV } \\
\text { decrease } \\
\text { from } 7.7 \text { to } 5.79\end{array}$ & $6 / 9(67 \%)^{\ddagger}$ \\
\hline \multicolumn{10}{|c|}{ 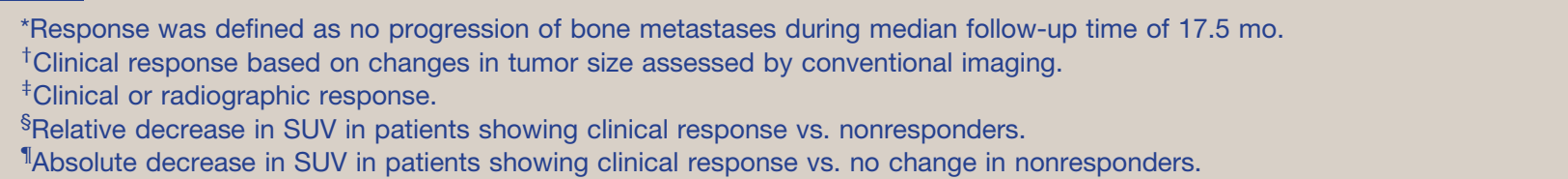 } \\
\hline
\end{tabular}

tially benefit most from the early identification of ineffective treatments, particularly in cases of metastatic breast cancer, because various alternative treatment options are available; in addition, patients could be spared the toxicities of ineffective treatments.

Weber et al. proposed defining the metabolic response as a decrease in the SUV larger than 2 times the SD (20\%) of spontaneous changes in ${ }^{18} \mathrm{~F}$-FDG uptake $(51,52)$. In a study of breast cancer, a decrease in ${ }^{18} \mathrm{~F}$-FDG uptake of more than $20 \%$ compared with the baseline correctly identified 5 of 7 nonresponding lesions (71.2\%) and 12 of 14 responding lesions (85.7\%) after the first cycle of chemotherapy (50). A specific strength of ${ }^{18} \mathrm{~F}$-FDG PET appears to be the identification of nonresponders, who are characterized by virtually no change in ${ }^{18} \mathrm{~F}$-FDG uptake after the initiation of chemotherapy. The overall survival of patients not showing a metabolic response was $8.8 \pm 6.7 \mathrm{mo}$, and that of patients showing a metabolic response was $19.2 \pm 13.6$ mo (50). An important finding of that study (50) was that 14 cycles of chemotherapy could be avoided in 5 nonresponding patients.

Importantly, the pattern of changes in glucose metabolism also depends on the type of therapeutic agent. For example, a transient increase in glucose metabolism followed by a decrease in ${ }^{18} \mathrm{~F}-\mathrm{FDG}$ uptake has been observed for tumors responding to hormone therapy with tamoxifen. Dehdashti et al. (53) studied 11 women with ${ }^{18}$ F-FDG PET before and approximately $1 \mathrm{wk}$ after the initiation of tamoxifen therapy. Seven patients who responded on the basis of clinical and radiologic follow-up showed an initial increase in ${ }^{18} \mathrm{~F}-\mathrm{FDG}$ uptake $1 \mathrm{wk}$ after the initiation of therapy. An explanation for this "metabolic flare" phenomenon is that tamoxifen has initial agonist effects before antagonist effects dominate. Clinically, this effect occurs within the first 1-2 wk of treatment and is characterized by erythema of soft-tissue lesions and increased pain in osseous metastases. The same group of investigators confirmed their findings in a larger series (54). In patients responding to tamoxifen, tumor ${ }^{18} \mathrm{~F}$-FDG uptake increased by $28.4 \%$, and only 5 of these patients showed evidence of a clinical metabolic flare reaction. In nonresponding patients, no significant change in tumor ${ }^{18} \mathrm{~F}-\mathrm{FDG}$ uptake compared with the baseline was observed. Importantly, so far there have been no reports of a metabolic flare in chemotherapeutic regimens, nor is the response known to occur with the newer endocrine agents (such as the aromatase inhibitors), which are now the treatment of choice for postmenopausal women.

In a recent comparison of ${ }^{18} \mathrm{~F}-\mathrm{FDG}$ PET and $16 \alpha^{-18} \mathrm{~F}-$ fluoroestradiol-17 $\beta$ ( ${ }^{18} \mathrm{~F}$-FES) PET, both the metabolic flare after estradiol challenge and the level of ${ }^{18} \mathrm{~F}$-FES uptake before endocrine therapy predicted the response to therapy (55). ${ }^{18} \mathrm{~F}$-FES uptake in breast cancer reflects estrogen receptor status, and an SUV of $\geq 2.0$ is considered positive for estrogen receptor expression. Fifty-one postmenopausal women with advanced estrogen receptorpositive breast cancer underwent ${ }^{18} \mathrm{~F}$-FES PET and ${ }^{18} \mathrm{~F}$ FDG PET scans at baseline and a second ${ }^{18}$ F-FDG PET 
scan after the administration of $30 \mathrm{mg}$ of estradiol. A $\geq 12 \%$ increase in the SUV for ${ }^{18} \mathrm{~F}$-FDG represented a metabolic flare and was therefore considered to indicate a response. After the estradiol challenge, only the responders showed a metabolic flare, with a significantly higher percentage change in the SUV for ${ }^{18} \mathrm{~F}-\mathrm{FDG}$ in responders $(20.9 \% \pm 24.2 \%)$ than in nonresponders $(-4.3 \% \pm 11.0 \%)$. On ${ }^{18} \mathrm{~F}$-FES PET, significantly higher uptake was noted in responders (SUV, $3.5 \pm 2.5$ ) than in nonresponders (SUV, $2.1 \pm 1.8$ ). ${ }^{18} \mathrm{~F}$-FES PET appears to be a promising approach for noninvasively determining the estrogen receptor status of metastatic breast cancer and predicting the response to endocrine therapy. Further trials are needed to clarify whether patients with low ${ }^{18} \mathrm{~F}$ FES uptake would benefit from more aggressive chemotherapy regimens.

\section{TREATMENT-INDUCED CHANGES IN TUMOR BLOOD FLOW}

The Seattle group has extensively studied ${ }^{15} \mathrm{O}$-water PET perfusion measurements in breast cancer and compared these measurements with glucose metabolism measured as the rate of ${ }^{18} \mathrm{~F}-\mathrm{FDG}$ metabolism (56-59). In 31 patients who underwent ${ }^{15} \mathrm{O}$-water perfusion and ${ }^{18} \mathrm{~F}$-FDG PET before the initiation of primary chemotherapy, high glucose metabolism normalized to blood flow was associated with a significantly poorer response to therapy (56).

Subsequently assessed changes in the rate of ${ }^{18} \mathrm{~F}-\mathrm{FDG}$ metabolism during primary chemotherapy revealed no significant correlation with histopathologic responses at the completion of treatment (57). In comparisons of relative changes in metabolic rates at baseline and midtherapy (2 mo after the initiation of chemotherapy), patients showing a histopathologic response had an average decrease in the metabolic rate of $65 \%$; for patients showing a partial response and patients not showing a response, the average decreases were $49 \%$ and $40 \%$, respectively. These findings are in line with those of previous studies demonstrating a good correlation between a decrease in tumor glucose metabolism measured as the SUV and a histopathologic response $(38-40)$. On the other hand, tumor blood flow decreased by $53 \%$ in patients showing a histopathologic response and by $12 \%$ in patients showing a partial response but increased, on average, by $45 \%$ in patients not showing a response. An important finding of that study (57) was that patients whose tumors failed to show a decrease in tumor blood flow after 2 mo of therapy had shorter disease-free survival and overall survival.

A series of 53 patients with locally advanced breast cancer were evaluated for changes in the rate of ${ }^{18} \mathrm{~F}-\mathrm{FDG}$ metabolism, ${ }^{18} \mathrm{~F}$-FDG blood-to-tissue transport $\left({ }^{18} \mathrm{~F}-\mathrm{FDG}\right.$ $K_{1}$ ), and tumor blood flow before and 2 mo after the initiation of primary chemotherapy (59). Patients who achieved a complete pathologic response had average decreases of $84 \%$ in the rate of ${ }^{18} \mathrm{~F}$-FDG metabolism,
$79 \%$ in ${ }^{18} \mathrm{~F}-\mathrm{FDG} K_{1}$, and $76 \%$ in tumor blood flow. In contrast, the average changes in nonresponding patients were $62 \%$ (rate of ${ }^{18} \mathrm{~F}-\mathrm{FDG}$ metabolism), $19 \%$ ( ${ }^{18} \mathrm{~F}-\mathrm{FDG}$ $K_{1}$ ), and $14 \%$ (tumor blood flow). Patients who had no significant decrease in tumor blood flow or ${ }^{18}$ F-FDG $K_{1}$ had a higher risk of recurrence and a higher mortality rate. Changes in tumor perfusion predicted disease-free survival and overall survival. The primary additional finding of that study (59) was the correlation of response and outcome with perfusion measurements, even more so than with changes in metabolism. The relationship between metabolism and blood flow was also shown to be predictive. The ability to predict responses on the basis of changes in tumor blood flow is encouraging, but further validation, including the definition of thresholds for changes in tumor perfusion, is needed to prove accurate identification of responses to therapy.

\section{MONITORING RESPONSE BY IMAGING CHANGES IN TUMOR CELL PROLIFERATION}

Imaging changes in tumor cell proliferation is an interesting new approach for monitoring therapeutic effects. Of the currently available PET proliferation tracers, ${ }^{18} \mathrm{~F}$ fluorothymidine $\left({ }^{18} \mathrm{~F}\right.$-FLT) has been the most extensively evaluated (60). In one of the first reports about ${ }^{18} \mathrm{~F}$-FLT PET in breast cancer, its use for diagnostic purposes was assessed (61). Increased ${ }^{18} \mathrm{~F}$-FLT uptake was noted in primary and metastatic breast cancer; however, the level of uptake was lower than that of ${ }^{18} \mathrm{~F}-\mathrm{FDG}$. A subsequent study revealed increased ${ }^{18} \mathrm{~F}$-FLT uptake predominately in larger primary tumors and axillary lymph node metastases (62).

${ }^{18}$ F-FLT PET for treatment monitoring in metastatic breast cancer detected changes in breast cancer proliferation $1 \mathrm{wk}$ after the initiation of combination chemotherapy with 5-fluorouracil, epirubicin, and cyclophosphamide (63). Eight patients were scanned twice before chemotherapy, and ${ }^{18}$ F-FLT uptake in 9 discrete tumor lesions was found to be reproducible, with a high test-retest correlation coefficient. Six patients had a significant reduction in ${ }^{18} \mathrm{~F}-$ FLT uptake at $1 \mathrm{wk}$ and a partial or complete clinical response later during treatment. In a study of 14 patients with newly diagnosed primary or metastatic breast cancer, ${ }^{18}$ F-FDG PET and ${ }^{18}$ F-FLT PET were performed at baseline, $2 \mathrm{wk}$ after the first cycle of a new treatment regimen, and after completion of the regimen (64). Changes in ${ }^{18} \mathrm{~F}-$ FLT uptake in primary and metastatic tumors after the first cycle were significantly correlated with the overall response. An interesting observation was that in most cases, the maximum tumor ${ }^{18} \mathrm{~F}$-FLT uptake assessed by dynamic data acquisition was reached within $10 \mathrm{~min}$ after tracer injection. The authors concluded that ${ }^{18}$ F-FLT PET performed $2 \mathrm{wk}$ after the end of the first cycle of chemotherapy is useful for predicting the longer-term efficacy of chemotherapy in breast cancer. 
To define the role of ${ }^{18}$ F-FLT PET in treatment monitoring in breast cancer, further validation with more patients is needed. A potential advantage of the use of ${ }^{18} \mathrm{~F}$-FLT is the early identification of therapeutic effectiveness, particularly in the evaluation of new biologic agents.

\section{ASSESSMENT OF RESPONSE TO TREATMENT WITH ${ }^{18}$ F-FDG PET AND PET/CT}

There are limited data on the role of ${ }^{18} \mathrm{~F}$-FDG PET and PET/CT in the assessment of a response after the completion of therapy in breast cancer. However, comparisons with conventional imaging procedures used for staging (CT, ultrasound, and MRI) revealed that metabolic whole-body PET has distinct advantages (Fig. 1). A recent meta-analysis of the diagnostic performance of ${ }^{18} \mathrm{~F}$-FDG PET in metastatic breast cancer included 18 articles published from January 1995 to June 2004 (65). In the studies with patientbased data, the median sensitivity was $92.7 \%$, and the median specificity was $81.6 \%$. The pooled sensitivity was $90 \%$, and the pooled false positivity rate was $11 \%$ after the exclusion of outliers. The maximum combined sensitivity and specificity was $88 \%$.

A distinct advantage of ${ }^{18} \mathrm{~F}-\mathrm{FDG}$ PET is the ability to assess tumor viability after previous treatments. Bony metastases are particularly difficult to evaluate because radiologic appearances often persist despite successful treatment. In a recent study, 146 bone metastases in 25 patients with recurrent breast cancer identified by ${ }^{18} \mathrm{~F}-\mathrm{FDG}$ PET/CT were monitored (66). After treatment, 58 osteolytic lesions $(80.5 \%)$ became ${ }^{18}$ F-FDG negative and osteoblastic on CT, with only 14 relatively large lesions (19.5\%) remaining ${ }^{18} \mathrm{~F}-\mathrm{FDG}$ avid. Of the $25{ }^{18} \mathrm{~F}-\mathrm{FDG}$-avid osteoblastic lesions, $13(52 \%)$ became ${ }^{18} \mathrm{~F}$-FDG negative, but 12 (48\%) remained ${ }^{18} \mathrm{~F}-\mathrm{FDG}$ avid and increased in size on $\mathrm{CT}$.

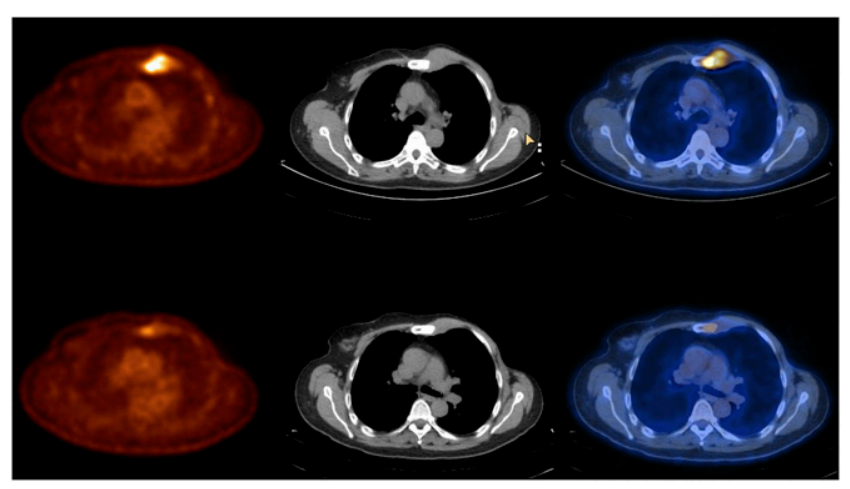

FIGURE 1. (Top row) Soft-tissue mass showing intense increase in ${ }^{18} \mathrm{~F}-\mathrm{FDG}$ uptake in left parasternal location in 59$y$-old woman with prior left mastectomy. (Bottom row) Mass decreased in size after completion of chemotherapy, and no abnormal metabolic activity was visualized-results consistent with good response to treatment. Panels from left to right represent ${ }^{18} \mathrm{~F}-\mathrm{FDG} \mathrm{PET}, \mathrm{CT}$, and fused ${ }^{18} \mathrm{~F}-\mathrm{FDG} \mathrm{PET} /$ CT images.
Five of the mixed-pattern lesions remained ${ }^{18} \mathrm{~F}-\mathrm{FDG}$ avid after treatment. All $17 \mathrm{CT}$-negative lesions became ${ }^{18} \mathrm{~F}$ FDG negative; however, 9 of them became osteoblastic. None of the initially ${ }^{18} \mathrm{~F}-\mathrm{FDG}-$ negative lesions showed increased metabolic activity during follow-up. The findings of that study (66) indicated that it is likely that ${ }^{18} \mathrm{~F}-\mathrm{FDG}$ uptake reflects the immediate tumor activity of bone metastases, whereas radiographically revealed morphologic changes vary greatly with time in patients. Another group of investigators recently compared morphologic and metabolic changes in bone metastases in response to systemic therapy in 102 patients (67). The progression of sclerotic changes after treatment was identified in 49 patients $(48 \%)$. Increases in attenuation on CT were significantly correlated with decreases in ${ }^{18}$ F-FDG uptake, and a decrease in the SUV after treatment was an independent predictor of a response.

With the increasing availability of PET/CT, the decision to use this imaging modality is becoming easier. There is increasing clinical evidence for breast cancer and other tumors that ${ }^{18} \mathrm{~F}-\mathrm{FDG}$ PET/CT after treatment is the most accurate procedure for the assessment of a treatment response when both CT information and tumor metabolic activity are considered.

\section{CONCLUSION}

In the United States, health insurance providers reimburse for monitoring of the response to treatment in breast cancer as an adjunct to standard imaging modalities for women with locally advanced and metastatic breast cancer when a change in therapy is anticipated. However, specific ${ }^{18}$ F-FDG PET criteria for determining a response or ineffective therapy have yet to be established. Generally, it appears to be possible to predict a response after the first cycle of chemotherapy. Such timing would have a notable clinical impact because patients receiving ineffective treatment could be switched to alternative therapies and responding patients could receive more aggressive chemotherapy.

There are several potential clinical applications for the PET-based prediction of a response to treatment with primary chemotherapy. First, metabolic imaging could identify breast cancer with low tumor metabolic activity before treatment; patients with such cancer might be more suitable candidates for surgery or hormone therapy. Second, patients for whom PET predicts a poor response after the first cycle of chemotherapy could be switched to alternative therapies earlier. The Aberdeen neoadjuvant chemotherapy trial (16) demonstrated improved overall survival with the addition of taxanes. In particular, patients showing clinical partial and complete responses benefited, but those not showing clinical responses did not greatly benefit. The use of metabolic imaging might offer better stratification of patients for optimal treatment and an earlier switch from ineffective chemotherapy. 
Importantly, the prediction of a clinically meaningful response to a particular chemotherapy regimen or drug remains a challenge. The concept of a response to treatment and therapy monitoring is complicated by the lack of an unequivocal definition of a response. For example, there is a fundamental difference between overall treatment efficacy and a complete pathologic response or a response assessed by changes in tumor size on the basis of RECIST. In a neoadjuvant chemotherapy trial (National Surgical Adjuvant Breast and Bowel Project Protocol B-27) (4), a 2 -fold increase in the rate of a pathologic complete response was observed when a taxane was added to a standard anthracycline-based chemotherapy regimen. However, this increase did not translate into an increase in overall survival. This finding raises the question of which response criteria should be used in assessments of novel drugs, new treatment regimens, or novel techniques, such as metabolic imaging. The response to chemotherapy is a continuous variable rather than a dichotomized one. Therefore, it may be important to establish response criteria that relate tumor response to patient outcome to guide subsequent treatment decisions. Therapy-induced changes in tumor glucose metabolism could play such a role.

The critical issue in the use of ${ }^{18} \mathrm{~F}$-FDG PET for monitoring and prediction of a response to treatment in the setting of metastatic disease is the accurate identification of ineffective treatment. For example, if a threshold of a 20\% decrease in the SUV after the first cycle of therapy is used to identify ineffective therapy, then serial ${ }^{18}$ F-FDG PET will not identify all nonresponding patients because some tumors might exhibit an initial decrease in ${ }^{18} \mathrm{~F}$-FDG uptake. On the other hand, clinically applicable thresholds need to be set so that treatment is not switched in patients who may be responding to first-line therapy. Therefore, cutoff thresholds for relative changes in ${ }^{18} \mathrm{~F}-\mathrm{FDG}$ uptake (SUV) must be carefully chosen and validated in prospective trials with a sufficient number of patients before chemotherapy can be discontinued or a treatment regimen can be changed. Finally, more information about PET treatment monitoring of endocrine and new biologic agents, such as trastuzumab, is also needed.

The current use of ${ }^{18} \mathrm{~F}$-FDG PET and PET/CT for treatment monitoring in breast cancer varies among institutions and reflects different practice in various countries. Important requirements are sufficient experience and dedication of the PET team to ensure the reproducible quantitation of tumor ${ }^{18} \mathrm{~F}-\mathrm{FDG}$ uptake. Generally, baseline ${ }^{18}$ F-FDG PET before systemic therapy provides an accurate assessment of the extent of disease, and ${ }^{18} \mathrm{~F}$-FDG PET approximately $6 \mathrm{wk}$ after the completion of therapy accurately reflects the response to treatment. Prediction of the therapeutic response by ${ }^{18} \mathrm{~F}$-FDG PET after the first or second cycle of therapy as well as early changes to alternative therapies in patients not showing a metabolic response should be done only in the context of clinical trials.

\section{REFERENCES}

1. Bonadonna G, Valagussa P, Zucali R, Salvadori B. Primary chemotherapy in surgically resectable breast cancer. CA Cancer J Clin. 1995;45:227-243.

2. van der Hage JA, van de Velde CJ, Julien JP, Tubiana-Hulin M, Vandervelden C, Duchateau L. Preoperative chemotherapy in primary operable breast cancer: results from the European Organization for Research and Treatment of Cancer trial 10902. J Clin Oncol. 2001;19:4224-4237.

3. Mauri D, Pavlidis N, Ioannidis JP. Neoadjuvant versus adjuvant systemic treatment in breast cancer: a meta-analysis. J Natl Cancer Inst. 2005;97:188194.

4. Bear HD, Anderson S, Smith RE, et al. Sequential preoperative or postoperative docetaxel added to preoperative doxorubicin plus cyclophosphamide for operable breast cancer: National Surgical Adjuvant Breast and Bowel Project Protocol B-27. J Clin Oncol. 2006;24:2019-2027.

5. Bonadonna G, Valagussa $P$, Brambilla $C$, et al. Primary chemotherapy in operable breast cancer: eight-year experience at the Milan Cancer Institute. J Clin Oncol. 1998;16:93-100.

6. Fisher ER, Wang J, Bryant J, Fisher B, Mamounas E, Wolmark N. Pathobiology of preoperative chemotherapy: findings from the National Surgical Adjuvant Breast and Bowel (NSABP) protocol B-18. Cancer. 2002;95:681-695.

7. Feldman LD, Hortobagyi GN, Buzdar AU, Ames FC, Blumenschein GR. Pathological assessment of response to induction chemotherapy in breast cancer. Cancer Res. 1986;46:2578-2581.

8. Kuerer HM, Newman LA, Smith TL, et al. Clinical course of breast cancer patients with complete pathologic primary tumor and axillary lymph node response to doxorubicin-based neoadjuvant chemotherapy. J Clin Oncol. 1999; 17:460-469.

9. Gralow JR, Burstein HJ, Wood W, et al. Preoperative therapy in invasive breast cancer: pathologic assessment and systemic therapy issues in operable disease. J Clin Oncol. 2008;26:814-819.

10. Hamilton A, Hortobagyi G. Chemotherapy: what progress in the last 5 years? J Clin Oncol. 2005;23:1760-1775.

11. Higgins MJ, Wolff AC. Therapeutic options in the management of metastatic breast cancer. Oncology. 2008;22:614-623.

12. Kilburn LS. 'Triple negative' breast cancer: a new area for phase III breast cancer clinical trials. Clin Oncol. 2008;20:35-39.

13. Ligibel JA, Winer EP. Trastuzumab/chemotherapy combinations in metastatic breast cancer. Semin Oncol. 2002;29:38-43.

14. Honkoop AH, van Diest PJ, de Jong JS, et al. Prognostic role of clinical, pathological and biological characteristics in patients with locally advanced breast cancer. Br J Cancer. 1998;77:621-626.

15. Bonadonna G, Veronesi U, Brambilla C, et al. Primary chemotherapy to avoid mastectomy in tumors with diameters of three centimeters or more. J Natl Cancer Inst. 1990;82:1539-1545.

16. Smith IC, Heys SD, Hutcheon AW, et al. Neoadjuvant chemotherapy in breast cancer: significantly enhanced response with docetaxel. J Clin Oncol. 2002;20: 1456-1466.

17. Sataloff DM, Mason BA, Prestipino AJ, Seinige UL, Lieber CP, Baloch Z. Pathologic response to induction chemotherapy in locally advanced carcinoma of the breast: a determinant of outcome. J Am Coll Surg. 1995;180:297-306.

18. Chevallier B, Roche H, Olivier JP, Chollet P, Hurteloup P. Inflammatory breast cancer: pilot study of intensive induction chemotherapy (FEC-HD) results in a high histologic response rate. Am J Clin Oncol. 1993;16:223-228.

19. Sinn HP, Schmid H, Junkermann H, et al. Histologic regression of breast cancer after primary (neoadjuvant) chemotherapy [in German]. Geburtshilfe Frauenheilkd. 1994;54:552-558.

20. Gajdos C, Tartter PI, Estabrook A, Gistrak MA, Jaffer S, Bleiweiss IJ. Relationship of clinical and pathologic response to neoadjuvant chemotherapy and outcome of locally advanced breast cancer. J Surg Oncol. 2002;80:4-11.

21. Ziegler LD, Connelly JH, Frye D, Smith TL, Hortobagyi GN. Lack of correlation between histologic findings and response to chemotherapy in metastatic breast cancer. Cancer. 1991;68:628-633.

22. Wolmark N, Wang J, Mamounas E, Bryant J, Fisher B. Preoperative chemotherapy in patients with operable breast cancer: nine-year results from National Surgical Adjuvant Breast and Bowel Project B-18. J Natl Cancer Inst Monogr. $2001 ;(30): 96-102$.

23. Fisher B, Bryant J, Wolmark N, et al. Effect of preoperative chemotherapy on the outcome of women with operable breast cancer. J Clin Oncol. 1998;16:26722685 .

24. Valero V, Buzdar AU, McNeese M, Singletary E, Hortobagyi GN. Primary chemotherapy in the treatment of breast cancer: the University of Texas M.D. Anderson Cancer Center experience. Clin Breast Cancer. 2002;3(suppl 2):S63S68. 
25. Machiavelli MR, Romero AO, Perez JE, et al. Prognostic significance of pathological response of primary tumor and metastatic axillary lymph nodes after neoadjuvant chemotherapy for locally advanced breast carcinoma. Cancer J Sci Am. 1998;4:125-131.

26. Chollet P, Amat S, Cure H, et al. Prognostic significance of a complete pathological response after induction chemotherapy in operable breast cancer. $\mathrm{Br}$ J Cancer. 2002;86:1041-1046.

27. Gonzalez-Angulo AM, McGuire SE, Buchholz TA, et al. Factors predictive of distant metastases in patients with breast cancer who have a pathologic complete response after neoadjuvant chemotherapy. J Clin Oncol. 2005;23:7098-7104.

28. Therasse P, Arbuck SG, Eisenhauer EA, et al. New guidelines to evaluate the response to treatment in solid tumors. European Organization for Research and Treatment of Cancer, National Cancer Institute of the United States, National Cancer Institute of Canada. J Natl Cancer Inst. 2000;92:205-216.

29. Chagpar AB, Middleton LP, Sahin AA, et al. Accuracy of physical examination, ultrasonography, and mammography in predicting residual pathologic tumor size in patients treated with neoadjuvant chemotherapy. Ann Surg. 2006;243:257264.

30. Yeh E, Slanetz P, Kopans DB, et al. Prospective comparison of mammography, sonography, and MRI in patients undergoing neoadjuvant chemotherapy for palpable breast cancer. AJR. 2005;184:868-877.

31. Denis F, Desbiez-Bourcier AV, Chapiron C, Arbion F, Body G, Brunereau L. Contrast enhanced magnetic resonance imaging underestimates residual disease following neoadjuvant docetaxel based chemotherapy for breast cancer. Eur J Surg Oncol. 2004;30:1069-1076.

32. Warren RM, Bobrow LG, Earl HM, et al. Can breast MRI help in the management of women with breast cancer treated by neoadjuvant chemotherapy? Br J Cancer. 2004;90:1349-1360.

33. Wasser K, Klein SK, Fink C, et al. Evaluation of neoadjuvant chemotherapeutic response of breast cancer using dynamic MRI with high temporal resolution. Eur Radiol. 2003;13:80-87.

34. Segara D, Krop IE, Garber JE, et al. Does MRI predict pathologic tumor response in women with breast cancer undergoing preoperative chemotherapy? $J$ Surg Oncol. 2007;96:474-480.

35. Martincich L, Montemurro F, De Rosa G, et al. Monitoring response to primary chemotherapy in breast cancer using dynamic contrast-enhanced magnetic resonance imaging. Breast Cancer Res Treat. 2004;83:67-76.

36. Wahl RL, Zasadny K, Helvie M, Hutchins GD, Weber B, Cody R. Metabolic monitoring of breast cancer chemohormonotherapy using positron emission tomography: initial evaluation. J Clin Oncol. 1993;11:2101-2111.

37. Weber WA. Positron emission tomography as an imaging biomarker. J Clin Oncol. 2006;24:3282-3292.

38. Schelling M, Avril N, Nährig J, et al. Positron emission tomography using $\left[{ }^{18} \mathrm{~F}\right]$ fluorodeoxyglucose for monitoring primary chemotherapy in breast cancer. $J$ Clin Oncol. 2000;18:1689-1695.

39. Smith IC, Welch AE, Hutcheon AW, et al. Positron emission tomography using $\left[{ }^{18} \mathrm{~F}\right]$-fluorodeoxy-D-glucose to predict the pathologic response of breast cancer to primary chemotherapy. J Clin Oncol. 2000;18:1676-1688.

40. Rousseau C, Devillers A, Sagan C, et al. Monitoring of early response to neoadjuvant chemotherapy in stage II and III breast cancer by $\left[{ }^{18} \mathrm{~F}\right]$ fluorodeoxyglucose positron emission tomography. J Clin Oncol. 2006;24:5366-5372.

41. McDermott GM, Welch A, Staff RT, et al. Monitoring primary breast cancer throughout chemotherapy using FDG-PET. Breast Cancer Res Treat. 2007;102: $75-84$.

42. Schwarz-Dose J, Untch M, Tiling R, et al. Monitoring primary systemic therapy of large and locally advanced breast cancer by using sequential positron emission tomography imaging with $\left[{ }^{18} \mathrm{~F}\right]$ fluorodeoxyglucose. J Clin Oncol. 2009;27:535541 .

43. Doot RK, Dunnwald LK, Schubert EK, et al. Dynamic and static approaches to quantifying ${ }^{18} \mathrm{~F}$-FDG uptake for measuring cancer response to therapy, including the effect of granulocyte CSF. J Nucl Med. 2007;48:920-925.

44. Hutcheon AW, Heys SD, Sarkar TK; Aberdeen Breast Group. Neoadjuvant docetaxel in locally advanced breast cancer. Breast Cancer Res Treat. 2003; 79(suppl 1):S19-S24.

45. von Minckwitz G, Blohmer JU, Raab G, et al. In vivo chemosensitivity-adapted preoperative chemotherapy in patients with early-stage breast cancer: the GEPARTRIO pilot study. Ann Oncol. 2005;16:56-63.

46. von Minckwitz G, Raab G, Caputo A, et al. Doxorubicin with cyclophosphamide followed by docetaxel every 21 days compared with doxorubicin and docetaxel every 14 days as preoperative treatment in operable breast cancer: the GEPARDUO study of the German Breast Group. J Clin Oncol. 2005;23:26762685 .
47. Jansson T, Westlin JE, Ahlstrom H, Lilja A, Langstrom B, Bergh J. Positron emission tomography studies in patients with locally advanced and/or metastatic breast cancer: a method for early therapy evaluation? J Clin Oncol. 1995;13: 1470-1477.

48. Gennari A, Donati S, Salvadori B, et al. Role of 2-[18 $\mathrm{F}]$-fluorodeoxyglucose (FDG) positron emission tomography (PET) in the early assessment of response to chemotherapy in metastatic breast cancer patients. Clin Breast Cancer. 2000; 1:156-161.

49. Specht JM, Tam SL, Kurland BF, et al. Serial 2- $\left[{ }^{18} \mathrm{~F}\right]$ fluoro-2-deoxy-D-glucose positron emission tomography (FDG-PET) to monitor treatment of bonedominant metastatic breast cancer predicts time to progression (TTP). Breast Cancer Res Treat. 2007;105:87-94.

50. Dose Schwarz J, Bader M, Jenicke L, Hemminger G, Janicke F, Avril N. Early prediction of response to chemotherapy in metastatic breast cancer using sequential ${ }^{18}$ F-FDG PET. J Nucl Med. 2005;46:1144-1150.

51. Weber WA, Petersen V, Schmidt B, et al. Positron emission tomography in nonsmall-cell lung cancer: prediction of response to chemotherapy by quantitative assessment of glucose use. J Clin Oncol. 2003;21:2651-2657.

52. Weber WA, Ziegler SI, Thodtmann R, Hanauske AR, Schwaiger M. Reproducibility of metabolic measurements in malignant tumors using FDG PET. J Nucl Med. 1999;40:1771-1777.

53. Dehdashti F, Flanagan FL, Mortimer JE, Katzenellenbogen JA, Welch MJ, Siegel BA. Positron emission tomographic assessment of "metabolic flare" to predict response of metastatic breast cancer to antiestrogen therapy. Eur J Nucl Med. 1999;26:51-56.

54. Mortimer JE, Dehdashti F, Siegel BA, Trinkaus K, Katzenellenbogen JA, Welch MJ. Metabolic flare: indicator of hormone responsiveness in advanced breast cancer. J Clin Oncol. 2001;19:2797-2803.

55. Dehdashti F, Mortimer JE, Trinkaus K, et al. PET-based estradiol challenge as a predictive biomarker of response to endocrine therapy in women with estrogenreceptor-positive breast cancer. Breast Cancer Res Treat. 2009;113:509-517.

56. Mankoff DA, Dunnwald LK, Gralow JR, et al. Blood flow and metabolism in locally advanced breast cancer: relationship to response to therapy. $\mathrm{J} \mathrm{Nucl} \mathrm{Med}$. 2002;43:500-509.

57. Mankoff DA, Dunnwald LK, Gralow JR, et al. Changes in blood flow and metabolism in locally advanced breast cancer treated with neoadjuvant chemotherapy. J Nucl Med. 2003;44:1806-1814.

58. Tseng J, Dunnwald LK, Schubert EK, et al. ${ }^{18}$ F-FDG kinetics in locally advanced breast cancer: correlation with tumor blood flow and changes in response to neoadjuvant chemotherapy. J Nucl Med. 2004;45:1829-1837.

59. Dunnwald LK, Gralow JR, Ellis GK, et al. Tumor metabolism and blood flow changes by positron emission tomography: relation to survival in patients treated with neoadjuvant chemotherapy for locally advanced breast cancer. J Clin Oncol. 2008;26:4449-4457.

60. Bading JR, Shields AF. Imaging of cell proliferation: status and prospects. J Nucl Med. 2008;49(suppl 2):64S-80S.

61. Smyczek-Gargya B, Fersis N, Dittmann H, et al. PET with $\left[{ }^{18} \mathrm{~F}\right]$ fluorothymidine for imaging of primary breast cancer: a pilot study. Eur J Nucl Med Mol Imaging. 2004;31:720-724.

62. Been LB, Elsinga PH, de Vries J, et al. Positron emission tomography in patients with breast cancer using ${ }^{18} \mathrm{~F}-3^{\prime}$-deoxy-3'-fluoro-L-thymidine $\left({ }^{18} \mathrm{~F}-\mathrm{FLT}\right)$ : a pilot study. Eur J Surg Oncol. 2006;32:39-43.

63. Kenny L, Coombes RC, Vigushin DM, Al-Nahhas A, Shousha S, Aboagye EO. Imaging early changes in proliferation at 1 week post chemotherapy: a pilot study in breast cancer patients with $3^{\prime}$-deoxy- $3^{\prime}-\left[{ }^{18} \mathrm{~F}\right]$ fluorothymidine positron emission tomography. Eur J Nucl Med Mol Imaging. 2007;34:1339-1347.

64. Pio BS, Park CK, Pietras R, et al. Usefulness of 3'-[F-18]fluoro-3'-deoxythymidine with positron emission tomography in predicting breast cancer response to therapy. Mol Imaging Biol. 2006;8:36-42.

65. Isasi CR, Moadel RM, Blaufox MD. A meta-analysis of FDG-PET for the evaluation of breast cancer recurrence and metastases. Breast Cancer Res Treat. 2005;90:105-112.

66. Du Y, Cullum I, Illidge TM, Ell PJ. Fusion of metabolic function and morphology: sequential $\left[{ }^{18} \mathrm{~F}\right]$ fluorodeoxyglucose positron-emission tomography/ computed tomography studies yield new insights into the natural history of bone metastases in breast cancer. J Clin Oncol. 2007;25:3440-3447.

67. Tateishi U, Gamez C, Dawood S, Yeung HW, Cristofanilli M, Macapinlac HA. Bone metastases in patients with metastatic breast cancer: morphologic and metabolic monitoring of response to systemic therapy with integrated PET/CT. Radiology. 2008;247:189-196. 